Nordisk Tidsskrift for Kriminalvidenskab 2004

\title{
BROTTSUTVECKLINGEN I FINLAND 1980-2002
}

\section{AV DIREKTÖR KAUKO AROMAA}

Trends in crime may be largely explained by variations in three basic dimensions of the crime environment. These are the supply of motivated offenders, the supply of crime opportunities, and the presence or absence of competent control. Depending on the size and overlap of these three factors, variations in the structure and volume of "crime" can be explained. Since the interplay of these factors occurs within the framework of crime definitions, changes in what is criminalized will, of course, change this framework and explain variations emanating from this source. When interpreting crime rates as recorded by control authorities, a further problem must be taken into account: the rate at which crimes are recorded and registered is an important intervening variable that hampers simple interpretations of recorded crime. Since important changes have been periodically observed in all of these factors, extreme caution should be exercised when using official police data to make decisions relevant to criminal policy. Complementary sources of information are presently available that make it somewhat easier to interpret trends in specific forms of crime.

According to available data, the overall crime situation in Finland has changed relatively little during the past 20 years, with the exception of a steady increase in narcotics crime since the early 1990s. Arguments concerning the "ownership" of crime problems and disagreements over which forms of data are best suited for interpretations and policy recommendations has become more marked over time, indicating that criminal policy is becoming increasingly politicised. Crime policy is thus affected more by which camp wins this paradigmatic struggle than it is by the "actual" trends in crime revealed through empirical analysis. Demographic changes in the age of the population mean that older members of society are gaining more weight in policy decision-making, including decisions regarding the definition of criminal policy problems and solutions. This, together with the growing domination of the market ideology, is contributing to the development of a punitive criminal policy that is fast replacing the social welfare model, which dominated at least in the 1960s and 1970s.

\footnotetext{
* Title in English: Crime Trends in Finland from 1980 to 2002. Original in Swedish.
} 


\section{Inledning}

I sin översikt av brottsutvecklingen i Finland 1950-1982 analyserar Patrik Törnudd (1984) sammanhangen mellan brott och samhällsutveckling. Han hävdar att samhällsförändringen förorsakar förändringar i brottstillfällen, motivation och definition, och det är förändringar i dessa dimensioner som i stort sett förklarar förändringar i den registrerade brottsligheten. Törnudd skriver: "Åren 1950-1982 inrymmer en period av unika strukturförändringar i Finland. Övergången från agrarsamhälle till industrisamhälle skedde senare och snabbare i Finland än i övriga nordiska länder. 1960-talet och början av 1970-talet kännetecknas av en ovanligt omfattande inre migration till städerna och industriorterna i södra Finland. Samtidigt nådde de stora födelsekohorterna som föddes efter kriget brottsintensiv ålder. Inverkan av dessa stora samhällsförändringar kommer klart till synes i utvecklingen av brottsligheten. - I första hand kan strukturförändringarna förväntas öka antalet brottstillfällen. För det stora flertalet brottsarter gäller att tätorter erbjuder fler möjligheter att begå brott än landsbygden. Detta gäller inte blott "tillfällen" i ordets mest konkreta bemärkelse: antal stöldobjekt eller tillgången på supkamrater att råka i slagsmål med: Med tilltagande urbanisering och ekonomiskt växt följer också ofta att den genomsnittliga bevakningsintensiteten per brottsobjekt minskar och att kontrollen i risksituationer överlag försvagas.... I ett urbaniserat samhälle är.. det sociala trycket att bete sig normenligt i flera avseenden svagare... Samhällsförändringarna har förskjutit balansen mellan brottsstimulerande och tillbakahållande krafter: motivationen för brottsligt beteende är en annan i dag än i det tidiga 1950-talets agrara Finland.... den... pedantiska inriktningen på registrering av även relativt lindriga förseelser. Den stora anhopningen av lindriga brott i kriminalstatistiken gör den mycket känslig för även små förskjutningar i lagtolknings-, anmälnings- och registreringspraxis... den registrerade brottsligheten påverkas av förskjutningar i brottsdefinitionen..." (Törnudd 1984: 149-150).

De centrala idéerna i detta resonemang gäller även utvecklingen efter 1980. Åter kan vi skönja nya unika samhällsförändringar vilka förmår förklara en hel del av de nyare trenderna - dels är det en förlängning framåt av de faktorer som Törnudd påpekar, dels är det nya fenomen som återigen har förvandlat vår brottsomgivning på olika sätt som förklarar varför vissa förändringar i brottsligheten har kommit till.

Frågan om registrerade brott och den dolda brottsligheten är mycket central i diskussionen om tolkningarna av brottsstatistiken. Det är väl känt att de polisregistrerade siffrorna är bara ett dåligt mått för de brott som egentligen har hänt. Dessa siffror är dock fortfarande den vanligaste utgångspunkten av analyser av brottslighetsläget och -utvecklingen. Detta beror på att bättre kompletterande statistikserier inte är allmänt tillgängliga, fast situationen ju har förbättrats dra- 
matiskt under de senaste två decennierna. I synnerhet har standardiserade brottsofferundersökningar etablerats i många länder inklusive Finland, och likaså har i flera länder något liknande uppnåtts i området självrapporterad brottslighet. Dylika kompletterande källor visar med all säkerhet, att den dolda brottsligheten är av massiv storleksordning. Detta åter betyder att även små förskjutningar i balansen mellan registrerad och dold brottslighet kan åstadkomma betydande förändringar i den polisproducerade brottsstatistiken vilken även därför bör hanteras försiktigt som källa om den "verkliga" situationen. Om den har gjorts väl och på ett väl standardiserat sätt så är den bra för att beskriva/mäta exakt vad namnet antyder: brott registrerade av polisen - alltså det som polisen får till kännedom och räknar.

Efter 1980 har anmälningsbenägenheten av misshandel, stöld och skadegörelse ökat på ett markant sätt, och polisens informationssystem har blivit mer omfattande och exakt med mer enhetliga regler för antalsräkning och mer automatiserade registreringsprocesser. Båda nämnda mekanismer har bidragit till ökningen av den polisregistrerade brottsligheten överlag. Därtill har väl även den reella brottsligheten i många fall ökat mer än befolkningen: det är de mångfaldiga och stadigt ökande brottstillfällena och den bristande kontrollen, tillsammans med den ökande motivationsfaktorn i det moderna stadssamhället, som alla stödjer detta antagande kraftigt - samma mekanismer som även Törnudd påpekade.

Samhällsförändringarna i Finland efter 1980 kan vi försöka beskriva med några av Törnudds valda indikatorer: Nylands läns andel av totalbefolkningen har inte mera tilltagit märkbart. Med stadsbefolkningens andel har detsamma hänt. Antalet män i åldern 15-24 har åter gått ner då de stora efterkrigsårskullarna har passerat denna åldersgrupp och är idag lika stor som den var på 1950-talet. Antalet bilar har stadigt ökat, från 7 per 1000 invånare år 1950 till 256 år 1980, 388 år 1990 och 412 år 2000. Alkoholkonsumtionen i 100-\%:ig alkohol per capita har ökat från 1,7 år 1950 till 6,3 år 1980, och senare upp till 9,0 liter år 2001.

Idag kan förändringar i brottslighetsläget förstås så att de bestämmas av tre centrala dimensioner genom vilka samhällsförändringen projiceras till omständigheter som gynnar eller förhindrar att brott händer. Samhällsförändringar förorsakar förändringar 1) i volymen och strukturen av potentiella brottslingar/gärningsmän; 2) i volymen och strukturen av lämpliga brottsoffer och brottmål; och 3) i krafter som förebygger/förhindrar att brott begås/sker (till dessa krafter hänvisas här med begreppet kontroll). I detta perspektiv varierar incidensen av vissa/olika brott med förändringar i dessa tre grundläggande element av brott. 
Volymen av en given typ av brott är en komplex funktion av samspelet mellan vissa fundamentala dimensioner på fältet - motivation, tillfälle, kontroll. Därtill behöver definitionsnivån granskas: varje samhälle har sin egen strafflagstifting och avgör därmed innehållet i sin brottslighet och sin kriminalpolitik.

I dagens samhälle som genomgår en utveckling som hänger ihop med europeisk och global integration, kan vi urskilja fem allmänna förändringar som förorsakar förändringar i vår brottslighet:

1) Lokala nätverk som upprätthåller den informella sociala kontrollen försvagas. Nätverken försvagas då den accelererande migrationen inom landet försvagar kontrollpotentialen av lokala grann-, kännedoms- och vänskapsnätverk.

2) Omständigheter som gynnar organiserad kriminell verksamhet och organisationbrottslighet blir bättre. Ekonomiska transaktioners frihet förbättrar omständigheterna som även gynnar aktörer inom den illegala ekonomin.

3) Nya former av brottsteknik och brottsformer kommer fram som "importvara" dels genom medial spridning av lärdomar/förebilder dels genom konkret import i och med att gärningsmännen är mer mobila än tidigare. Den snabba expansionen av narkotikamarknaden är ett vanligt exempel på nya brottsformer som börjar breda ut sig som "importföreteelser"; många andra innovationer påträffas. Att ett ökande antal invandrare även har kommit till Finland reflekteras också i att diskrimineringsbrott har i ökande grad registrerats, såsom också andra brott som förekommer i konflikter mellan invandrare och den finska befolkningen.

4) Den ökande invandringen har betydelse. Invandrarna blir med tiden "hembaser" för andra, även kriminellt aktiva personer från invandrarnas hembygder. Sådana personer/grupper kan få skydd, instruktioner om de lokala omständigheterna, och kontakter till lokala medhjälpare som kan behövas i olika kriminella projekt. Något likadant hände till exempel under 1960-talet i Sverige när ett stort antal av finska medborgare emigrerade met tanke på bättre sysselsättningsmöjligheter.

5) Den kriminella undre världen integreras. Integrationen av olika marknader gäller också professionella kriminella marknader. Den finska professionella organiserade brottsligheten är även fortsättningsvis mestadels av lokal karaktär, som har samarbets- och konkurrensrelationer till utländska organiserade brottslingsgrupper, mestadels från grannländerna. Därtill, alltså utöver dessa fem trender kan vi urskilja två unika lokala förändringstrender som är karakteristiska för Finland under senaste två decennierna. Dessa är: 
6) Urbaniserigen accelererade under 1990-talet, och koncentrationstendensen av befolkningen till några få tillväxtcentra fortsätter. Processen hade börjat redan innan Finland blev medlem i EU, men en del av den nyaste utvecklingen är direkt beroende av finanspolitiken som påverkats av denna medlemskap. De stora befolkningskoncentrationerna börjar utveckla en ekonomisk segregation vilket kan tillbringa problem som vi tidigare har gjort bekantskap med i utländska metropoler.

7) En polariseringstendens som gäller levnadsförhållanden av den lokala befolkningen har börjat och fortsätter. Den ekonomiska recessionen under tidiga 1990-talet har tillsynes lämnat långvariga spår åtminstone $\mathrm{i}$ en relevant betydelse. Finanspolitiken efter recessionen har främjat (eller inte kunnat förhindra) en utveckling av ojämlikhet och polarisering - och därför även tillkomsten av marginaliserade befolkningsgrupper. Denna process har under senare tider även kryddats genom en ökande invandring till Finland. Befolkningen blir i ökande grad multinationell, och riskgrupperna växer som en följd av polariseringsutvecklingen och av nedskärningspolitiken som påverkar den allmänna sektorn. I detta nya läge ökar populariteten av många aktiviteter som lämpar sig för att göra illegala pengar.

Detta gäller många ulika profitproducerande brott, bl.a. stöld, bedrägeri, smuggling eller narkotikahandel, och detsamma gäller brott inom den ekonomiska sektorn (konkurs- eller skattebrott). För den unga generationen kan dylika framtidsperspektiv vara synnerligen relevanta då tillfällena att göra brottsliga pengar förbättras samtidigt som traditionella alternativ för framgång håller på att bli alltmer begränsade i och med den ökande konkurrensen. 
2. Allmänna uppgifter om brottslighetsläget och -utvecklingen fr.o.m. 1980 I polisstatistiken registrerar man som huvudregel enskilda brott, dvs. händelser. Statistikföringsenheten är det enskilda brottet, inte gärningsmannen.

Tabell 1. Av polisen registrerade brott mot strafflagen 1960 - 2002

\begin{tabular}{lc} 
År & Antal \\
\hline 1960 & 69472 \\
1965 & 88045 \\
1970 & 132138 \\
1975 & 209602 \\
1980 & 221106 \\
1985 & 291551 \\
1990 & 435154 \\
1995 & 381652 \\
2000 & 530270 \\
2001 & 516175 \\
2002 & 520194 \\
\hline
\end{tabular}

Volymen av registrerade brott mot strafflagen 2002 är ca 7,5 gånger så stor som siffran för 1960 och nästan 2,5 gånger så stor som siffran för 1980. I stort sett har omfånget av brotten mot strafflagen, alltså brottsdefinitionerna, inte massivt förändrats även om vissa nya brottstyper - såsom rattfylleri och våldtäkt inom äktenskapet - har tagits in, och andra brott - såsom misshandel - har fått en bredare definition än förut. Detta betyder inte enbart att brottstillfällena och de faktiska brottena kraftigt har ökat, och att anmälningsbenägenheten har ökat, utan även att brottsregistreringen har blivit mer noggrann och effektiv.

Tabell 2. Utvecklingen i vissa brottstyper 1980-2002: polisregistrerade brott mot strafflagen per tiotusen invånare

År Stöldbrott Våldsbrott Sexual- Narkotika- Rattfylleri Alla brott mot brott brott strafflagen

\begin{tabular}{rrrrrrr}
\hline 1980 & 228 & 30 & 2,3 & 2,0 & 43 & 462 \\
1985 & 272 & 34 & 6,4 & 4,7 & 43 & 594 \\
1990 & 364 & 42 & 2,0 & 5,1 & 60 & 871 \\
1995 & 397 & 44 & 2,2 & 18 & 41 & 746 \\
2000 & 424 & 55 & 2,5 & 26 & 44 & 1023 \\
2001 & 387 & 54 & 2,4 & 29 & 44 & 994 \\
\hline
\end{tabular}




\subsection{Mord och dråp}

Mord och dråp har i Finland varit på en avsevärt högre nivå än i övriga västliga Europa eller de övriga nordiska länderna så länge som det finns statistikkällor om saken. Under den första granskningsperioden upplevde Finland en kraftig och permanent ökning av denna nivå. Denna ökning tillskrivs vanligtvis den snabbt ökade alkoholkonsumtionen och den kraftiga migrationen samt den snabba urbaniseringen på 1960-talet. Därefter stagnerade antalet av mord och dråp på den nya högre nivån fram till 1990-talet. Då observerades en ny ökning som hade en speciell karaktär: den koncentrerade sig praktiskt taget totalt till en relativt liten befolkningsgrupp som bestod av marginaliserade yngre män. Denna sårbara specialgrupp skapades uppenbart genom recessionen under det tidiga 1990-talet, den rekryterades från den stora mängden utslagna som då för gott utstöttes från aktivbefolkningen. I kontrast till den tidigare situationen medförde detta att genomsnittsåldern för delaktiga i dessa brott gick ned eftersom den nyrekryterade gruppen bestod av yngre personer än de som mer traditionellt dräpte varandra. Under de senaste åren tycks effekten av denna engångsfaktor ha dragit sig tillbaka. Samtidigt har de stora kohorterna som föddes efter kriget blivit så gamla att deras mord- och dråpintensitet har börjat avta - och antalen mord och dråp håller på att sjunka småningom så att den kommer igen närmare 1960-talsnivån. (Mekanismerna är säkerligen mer komplexa än vad som beskrivs här.)

Trenden för mord och dråp i Finland håller på att reflektera en tvådimensionell utveckling. För det första håller de stora efterkrigstida födelsekohorterna på att föråldras så starkt att deras kapacitet att begå mord och dråp börjar avta: de håller på att överskrida åldern med en hög risk för mord och dråp (Också: de har kommit så långt att personer med den största sannolikheten att bli dräpta redan har dräpts). Av nämnda orsaker borde antalet mord och dråp inom denna grupp börja sjunka. Samtidigt har en ny högriskgrupp uppstått: unga (i 20-30årsåldern) marginaliserade personer, vanligtvis av manligt kön. Den gruppen består av personer som drabbades värst av den stora ekonomiska strukturomvandlingen efter tidiga 1990-talets recession/depression och förvandlades till en ny paria-klass av enorm storleksklass. Det är denna grupp som svarar för den största delen av ökningen av antalet mord och dråp under det senaste decenniet, både som gärningsmän och som offer. Denna grupp kompenserar åldringseffekten av befolkningen som beskrevs ovan. Härtill kommer två nya mindre tillväxtelement; det ena är den relativt nya uppkomsten av gangsterdråp vilka idag svarar för ett flertal (en handfull) mord och dråp på årsnivå; den andra nyheten är att mord och dråp där unga personer (åldersgrupper under 20 år) är involverade har ökat något under det senaste decenniet. Ett nytt problem förorsakas eventuelt av den kraftiga sänkningen av alkoholpriserna som är en konsekvens av Finlands EU-medlemskap. Detta förväntas öka alkoholkonsumtionen i en betydande grad. 
Med den rådande konsumtionsstrukturen förväntas detta åstadkomma ett ökat antal akuta alkoholproblem - och med en viss fördröjning även långtidsproblem $\mathrm{i}$ grova drag på samma sätt som Finland upplevde sent på 1960-talet och tidigt på 1970talet och senare. En för mildrande omständighet här är att befolkningen som denna förändring angår redan för det mesta är bosatt i städer och inte håller på att flytta $i$ stora massor från landsbydgen till städerna, och att de yngre årskullarna som förra gången värst drabbades, idag är avsevärt mindre än på 1960-1970-talet. Den förväntade nya ökningen av antalet mord och dråp kommer därför kanske att inträffa gradvis och nå sin höjd först 5-10 år senare, och till en del skall den fortsättningsvis kompenseras av seniliseringen av efterkrigsårskullarna.

\subsection{Misshandelsbrott}

Misshandelsbrotten har systematiskt ökat i polisstatistiken, dels som en konsekvens av en starkt ökande rapporteringstendens - dvs. mörkertalet minskar -, dels genom lagändringar vilka dels likaså har påverkat registreringen av t.ex. kvinnomisshandel, men vilka dels har utvidgat definitionen av misshandel.

Fr.o.m. 1980 finns det en kompletterande källa som belyser förändringarna på ett centralt sätt: då påbörjades en serie av nationellt representativa befolkningsgrupper där relativt stora befolkningsgrupper utfrågas om deras offerupplevelser, bl.a. hot och våld. Samma undersökning har tillsvidare genomförts 1980, 1988, 1993, 1997 och 2003. Serien tyder på att uppgången av antalet misshandel som noteras i polisstatistiken under 1980-talet praktiskt taget helt beror på en ökning av anmälningsbenägenheten. Den förklarar i stort sett, att polisstatistiken visar en ökning på 30 \% 1980-1988, emedan offersiffrorna visar en lika tydlig nedgång. Efter 1988 har utvecklingen varit mindre dramatisk, offersiffrorna varierar på nivå. Polissiffrorna ökar fortsättningsvis efter en tillfällig nedgång $\mathrm{i}$ början av 1990-talet. Nedgången uppskattades vara av en reell karaktär och sammanhängde med den kraftiga ekonomiska recessionen Finland fick uppleva under den nämnda tiden. Serien visar också att en intressant och relevant strukturförändring har skett: våldet i parförhållanden eller familjevåldet har minskat något, samtidigt har hot och våld på arbetsplatser tilltagit praktiskt taget lineariskt från 1980 till 2003. Denna ökning har över hela perioden koncentrerats i en befolkningsgrupp: kvinnor i serviceyrken, och i synnerhet i vårdbranschen.

En annan ny källa är den Internationella Brottsoffersurveyn ICVS. Inom detta program har 1989, 1992, 1996 och 2000 standardiserade befolkningsintervjuer genomförts på ett liknande sätt som i de finska nationella offerundersökningarna. Dessa mätningar använder ett mindre urval (ca 2000) och förmår därför inte nå samma rikedom av detaljer som de stora nationella undersökningarna. Deras styrka ligger i den jämförande dimensionen. De tyder på att den finska relativt höga misshandelsnivån (när man jämför polisstatistiken) i någon mån är 
reell, fast skillnaderna till övriga västeuropeiska länder inte är stora. Finland ligger här något över det europeiska genomsnittet men inte på toppen.

Tabell 3. Hot och våld i de riksomfattande offerstudierna 1980-2003: offer/händelser underi den föregående tolvmånadsperioden. Aldersgruppen 15-74.

\begin{tabular}{llll} 
År & $\begin{array}{l}\text { Offer \% } \\
\text { minst } \\
\text { en gång }\end{array}$ & $\begin{array}{l}\text { Anmälda till } \\
\text { polisen, \% av } \\
\text { händelser }\end{array}$ & $\begin{array}{l}\text { Uppskattade antalet } \\
\text { händelser }\end{array}$ \\
\hline 1980 & 10,2 & 3,7 & 629000 \\
1988 & 8,0 & 5,4 & 501000 \\
1993 & 8,3 & 6,6 & 533000 \\
1997 & 9,1 & 7,2 & 652000 \\
2003 & 10,5 & 7,2 & 627000 \\
\hline
\end{tabular}

\subsection{Våldtäkt}

I Törnudds rapport behandlades våldtäkt/sexualbrott inte separat. Gruppen är ju rätt liten. Våld inom äktenskapet kriminaliserades 1995. I praxis har dessa nya brott närmast varit våldtäkt av partner efter att förhållandet har upplösts. Lagstiftningen gällande sexualbrott förnyades helt fr.o.m. 1.1.1999. Antalet våldtäktsbrott har ökat under senare år. Antalet har varit över 500 på 2000-talet, medan nivån varierade kring 300 på 1980-talet och kring 400 på 1990-talet. Det finns få pålitliga källor om det riktiga antalet, och det förmodas ofta, att mörkertalet håller på att minska även vid dessa brott, fast det finns mycket som tyder på att det fortfarande är förödmjukande och pinsamt att göra anmälan om dessa brott. Offerenkäterna tyder på att mörkertalet fortfarande är mycket högt, i synnerhet när det gäller försök till våldtäkt och sexuella fysiska trakasserier. Av offerundersökningar kan uppskattas att våldtäkt och försök till våldtäkt består av ca 55000 fall på årsnivå vilket tyder på att anmälningsbenägenheten skulle ligga kring av 1 procent; ca. 60 procent av gärningsmännen var kvinnans nuvarande eller före detta partner.

\subsection{Rån}

Överlag har antalet rånbrott i polisstatistiken inte starkt varierat. Rånbrotten har samtidigt något förändrats $\mathrm{i}$ och med att gärningsmännen har blivit yngre. Även objekten har förändrats. Till exempel mobiltelefoner har blivit ett populärt rånobjekt. Vid rån är antalet brott så pass litet att vanliga offerundersökningar har svårigheter att producera numerära utvärderingar som skulle behövas för en uppskattning av möjliga trender. Rån begås mestadels i stadsmiljön av yngre manspersoner. Det gäller ofta gaturån. 
Bankrånen har nästan försvunnit i och med kraftiga förebyggande åtgärder efter 1992. Efter toppåret 1992 infördes en rad preventiva åtgärder vilka visade sig vara rätt effektiva. Det årliga antalet nämnda brott minskade från 120 till ett drygt tiotal, eller till ungefär nivån på 1980-talet. Bankkrisen och konsekvenserna därav var nog en bra hjälp i det här fallet, då bankerna gjorde en kraftig nedskärning av sina kontorsnätverk. Därför kan nedgången av antalet bankrån inte helt tillskrivas de förebyggande insatserna.

\subsection{Stöld}

Ökningen av antalet stöldbrott har stagnerat vid decennieskiftet 1980/1990. Under senare år har antalet gått något ner, och bortsett från snatteri är nedgången även rätt klar. Ser man närmare på stöld med inbrott så visar det sig att inbrotten nuförtiden domineras av bilinbrott medan inbrott i butiker går kraftigt ned, och inbrott i bostäder minskar på ett mer moderat sätt. Bilar är det snabbt ökande brottsobjektet i detta fall.

Offerundersökningar är en bra kompletterande informationskälla om stöldbrott såvitt frågan är om brott mot privat egendom (även vissa offerenkäter som syftar att mäta brott mot juridiska personer har genomförts men landsomfattande serier finns ännu inte tillgängliga). Enligt den Internationella Brottsofferundersökningen ICVS är lägenhetsinbrott i Finland på den lägsta nivån i Västeuropa. Den senaste finska nationella offerundersökningen år 2003 tyder på en allmän nedgång i brott mot privat egendom.

Tabell 4. Egendomsbrott mot personlig egendom enligt offerenkäter 1989 - 2003 (ICVS och de riksomfattande offerenkäten)

\begin{tabular}{lllllll} 
& 1989 & 1992 & 1996 & 1997 & 2000 & 2003 \\
\hline Bilstöld & 0,4 & 0,7 & 0,5 & 0,5 & 0,4 & 0,8 \\
Stöld från bil & 2,7 & 2,9 & 2,9 & 2,2 & 2,8 & 2,8 \\
Skadegörelse mot bil & 4,0 & 5,6 & 4,2 & 3,9 & 3,7 & 4,2 \\
Stöld av motorcykel & 0,0 & 0,3 & 0,2 & 0,1 & 0,1 & 0,1 \\
Stöld av cykel & 3,1 & 5,0 & 5,4 & 5,1 & 4,9 & 4,2 \\
Bostadsinbrott & 0,6 & 0,6 & 0,6 & 0,4 & 0,3 & 0,5 \\
Försök till bostadsinbrott & 0,4 & 0,5 & 0,7 & 0,6 & 0,9 & 0,5 \\
Stöld från person & 4,3 & 3,4 & 3,3 & 2,8 & 3,7 & 2,8 \\
Rån & 0,8 & 1,0 & 0,5 & 0,3 & 0,6 & 0,3
\end{tabular}

Offer vid något av de ovan nämnda brotten 


\subsection{Försnillning och bedrägeri $\mathrm{mm}$}

År 1991 förändrades statistikföringsreglerna för bedrägerier. Tidigare statistikfördes varje brottsligt bruk av kreditkort i en brottsserie separat. Detta förorsakade att den stora ökningen av antalet bedrägerier som hade observerats under hela 1980-talet försvann på en gång. Omläggningen medförde ca. 70000 färre brott jämfört med år 1990. Denna förändring var så markant att även totalsiffran för alla strafflagsbrott sjönk. Därefter har antalet nämnda brott stannat på en mycket jämn nivå, sannolikt en reflektion av att tillfällesstrukturen sedermera har varit relativt stabilt.

\subsection{Rattfylleri}

I och med den stora tillväxten av vägtrafiken har rattfylleribrottet småningom förlorat något av sin symboliska laddning som ett "centralt" brottsproblem. Brottet förekommer på en relativt stabil och låg nivå, även om det polisregistrerade antalet i första hand reflekterar kontrollinsatsen. Eftersom mörkertalet även vid dessa brott uppskattas vara rätt stort, kan även relativt små förskjutningar $\mathrm{i}$ kontrollinsatsen åstadkomma rejäla förändringar i antalet registrerade brott.

Registrerade rattfyllerifall är en funktion av trafikvolymen, alkoholkonsumtionen och trafikkontrollen. Tillsammans med en tillräcklig grad av övervakning och attitydkampanjer erbjuder tekniska innovationer som förhindrar rattfylleri ett lovande nytt element i kontrollen av denna brottstyp, kanske i kombination med bättre vårdinterventioner avsedda för problembilister med hög risk för återfall. Rattfyllerinivån verkar idag vara relativt stabil, även vägkantsundersökningar stödjer tolkningen.

\subsection{Narkotikabrott}

Efter den första narkotikaböljan i slutet av 1960-talet var situationen länge relativt lugn och begränsad. En förändring skadde först på 1990-talet. Från tidiga 1990-talet har antalet av narkotikabrott stadigt ökat förutom under ett par undantagsår, förmodligen på grund av en nyinriktning av kontrollinsatsen. Det huvudsakliga antalet utgörs av innehav och bruk, antalet grövsta brott förmår inte påverka totalvariationerna. Volymen av narkotikamarknaden kan antas fortsätta att öka, eftersom den inte ännu ligger nära nivån i de stora narkotikaländerna och transportmöjligheterna hela tiden förbättras, och därmed kan man förmoda att också yrkesmässigheten och organisationsgraden inklusive antalet involverade brottslingar - importörer, langare, mellanhänder - i branschen växer. Tillväxten behöver inte nödvändigtvis fortsätta så länge att konsumtionsnivån blir den samma som i de stora narkotikaländerna, men även den möjligheten måste tas $\mathrm{i}$ beaktande. 
Narkotikabrotten domineras av narkotikabruk. År 2001 infördes ett särskilt brott "narkotikabruk" som behandlas i en förenklad process med strafföreläggande. År 2002 var $52 \%$ av alla narkotikabrott narkotikabruk. Antalet grova narkotikabrott är litet jämfört med totalsiffrorna, exempelvis 760 av 13857 (5,5 \%) år 2002.

De registrerade narkotikabrotten beror närmast på storleken av och prioriteringarna inom kontrollinsatsen. Volymen av narkotikamarknaden har ökat kraftigt under de senaste decennierna, och denna trend kommer kanske inte att vända innan den finska marknaden har uppnått den volymen som redan kan observeras i de ledande västeuropeiska länderna. Narkotikahandelns höga vinster kommer att attrahera ett ökat antal förbrytare även i framtiden och fortsätter att skapa ett ökande problem av annan allvarlig brottslighet. Kontrollinsatsen har dock med tiden blivit starkare och mera professionell och samarbetet mellan myndigheterna i de relevanta länderna tilltar. Detta tillsammans med den starka alkohollutningen i det finska samhället kan ha som konsekvens att den framtida tillväxten blir rätt långsam.

Även om narkotikaläget finns det källor som är oberoende av myndighetsstatistiken, främst är det då enkätundersökningar som gjorts bland ungdomar. Dessa tyder på att en stadig ökning fortsätter men bara på en moderat nivå.

\subsection{Organiserad, ekonomisk och professionell brottslighet}

Förutom narkotika har även andra mycket profitabla marknader uppstått. Med globaliseringen har tobak, alkohol, skjutvapen, människor blivit attraktiva illegala handelsvaror. Detta implikerar att omfattande illegala affärer idag är ett permanent problem för brottslighetskontrollen, och deras betydelse i uppfostran av yrkesmässiga persistenta brottslingar måste vara ansenlig. En av de centrala krafter som underlättar dylika operationer och gör dem profitabla är de stora inkomstskillnanderna mellan länderna, och därtill kommer de stora skatteskillnaderna som tillsammans betyder att detta problem inte kommer att minska inom kort. Om den legala arbetsmarknaden inte förmår skapa tillräckliga sysselsättningsmöjligheter som kan konkurrera med de illegala alternativen, kommer brottslighetskontrollen att uppleva en rätt allvarlig och permanent uppmaning.

Enligt Centralkriminalpolisens kartläggning av situationen i Finland är läget gällande den organiserade brottsligheten relativt begränsad. Antalet organiserade grupper som har observerats har gått upp till 30. Dessa omfattar några mc-gäng, men i huvudsak är det grupper som håller på med narkotikahandel, prostitution, sprit- och tobakssmuggling. Volymen av verksamheten har småningom ökat. Samarbete med utländska, främst estniska och i viss mån ryska grupper förekommer. 


\subsection{0. Övriga brott}

Övriga, nya, eller på ett nytt sätt definierade typer av brott är alltid intressanta. Men det går knappast an att göra en systematisk statistisk genomgång av sådant som IT-brott, cybercrime, organiserad brottslighet, människohandel, annat vad som på senare tid har prioriterats bl.a. i den internationella kriminalpolitiska debatten, där även terroristfenomenet ingår mycket kraftigt, och korruption, liksom redan före detta hände med våld mot kvinnor, våld i familjen (mot barn, åldringar $\mathrm{mm}$ !), eller diskrimineringsbrott (USA, EU, FN, ER osv. har varit de aktiva debattörerna och fora i dylika fall). När den debatten har uppstått fortsätter de stora linjerna i stort sett som förut. Och typiskt nog så har de nyligen upptagna brotten vanligtvis ett mycket litet utslag på fältet men en stor betydelse för utvecklingen av kontrollen, av polisbefogenheterna och försöken att begränsa medborgarnas människorättigheter.

\section{Framtiden}

Oro, rädsla, otrygghet eller bekymmer som vållas av brottslighet och brotts-lighetens representation i medierna tycks hålla på att växa. Urbaniseringen och den därmed framskridande anonymiseringen av vardagslivet, den begränsade tillgången till realistisk information om brottsrisker, och det faktum att en ökande och även dominerande andel av befolkningen i stort sett är beroende av information från sekundärkällor istället för sin egen förstahandserfarenhet (mediaexplosionen tillsammans med det faktum att vardagliga brott är rätt sällsynta i befolkningens personliga erfarenhetskrets), tillsammans med att befolkningen åldras i snabb takt - har skapat en ond cirkel av ökande oro och rädsla, vilken bör noteras som ett självständigt och betydande samhällsproblem. Denna utveckling förorsakar en försämring av levnadskvalitén. En konsekvens kan vara att politiskt beslutsfattande som har med brottslighet att göra kommer att i ökande grad bero på hotbilder, oro och rädsla. Befolkningsenkäter som gjorts i ett antal västeuropeiska länder tyder på att detta fenomen håller på att förvärras med tiden: rädsla, oro och känslor av otrygghet som relaterar till brottslighet är systematiskt mer allmänna i de stora industrialiserade västeuropeiska länderna än i Finland, och kriminalpolitiska teman har fått en allt större vikt i valdebatter.

Det nordiska välfärdssamhället är fortfarande i relativt gott skick i Finland, men situationen håller på att försämras. I flera kommentarer har hävdats att det är just detta sakläge som har skyddat Finland på senare tid så pass väl att brottsproblemen inte har uppnått en högre nivå än vad faktiskt har inträffat. Det finska brottslighetsläget har forblivit relativt stabilt, fast den europeiska tillväxten av narkotikamarknaden även har nått Finland. Förändringarna som har inträffat håller dock på att förorsaka ett växande tryck för en mer kunskapsbaserad kriminalpolitik. I förhållanden där förändringarna är snabba blir det i ökande grad sannolikt att dåligt motiverade och falska beslut kommer att fattas om inte den 
adekvata kunskapsbasen är tillgänglig. Detta betyder att kraven som gäller kvalitén av den kriminalpolitiska planeringen och forskningen som erbjuder grundvalen till denna håller på att växa. Det blir viktigare än förut att investera i systematiskt, vetenskapligt brottsförebyggande och i att få bättre information om brottsligheten och brottslighetskontrollen, om brottsoffer och brottsskador, och även om hur man integrerar dömda förbrytare tillbaka till normalsamhället.

Adress:

Europeiska Institutet för Kriminalpolitik, verksamt i samband med Förenta Nationerna (HEUNI)

POB 157, 00121 Helsinki

Tel. +358916067881

Fax + 358916067890

E-mail kauko.aromaa@om.fi 